Revista de Ensino em Artes, Moda e Design

Dossiê 4

Currículo: espaço de reflexão e poder

\title{
REFORMAS CURRICULARES NO CURSO DE ARTES VISUAIS DA UNIVERSIDADE DO ESTADO DE SANTA CATARINA - UDESC
}

\section{Curricular Reforms in the Visual Arts course of the State University of Santa Catarina - Udesc}

\section{Paula Rodrigues Correia ${ }^{1}$}

\section{Tatiane Rebelatto ${ }^{2}$}

1 É graduada em Design de Moda pela Faculdade Católica do Ceará e graduada em Artes Plásticas pelo Instituto Federal de Educação, Ciência e Tecnologia do Ceará - IFCE, mestra em Design pela Universidade Anhembi Morumbi de São Paulo - UAM e especialista em Teorias da Comunicação e da Imagem pela Universidade Federal do Ceará - UFC. Atualmente é doutoranda no Programa de Pós-Graduação em Artes Visuais - PPGAV/UDESC, professora no Curso de Bacharelado em Moda na mesma instituição e também atua como docente nos cursos livres do Departamento Artístico e Cultural - DAC/UFSC em Florianópolis.

E-mail: paulailustra@gmail.com | Lattes: http://lattes.cnpq.br/5496538818521847

2 Formou-se em Artes Visuais pela Universidade Federal de Santa Maria - UFSM/RS, é mestra em História pelo Programa de Pós-Graduação em História - PPGH/UDESC e atualmente é doutoranda em Artes Visuais pela mesma instituição - PPGAV/UDESC.

E-mail: tatirebelatto@hotmail.com | Lattes: http://lattes.cnpq.br/1171169963129518 


\title{
Resumo
}

Diante da proposta de reforma curricular que se pretende fazer nos cursos de Artes Visuais da Universidade do Estado de Santa Catarina, buscou-se entrevistar uma das professoras do Núcleo Docente Estruturante do curso de graduação para comentar sobre essa proposta, bem como explicar os objetivos e desafios enfrentados na reforma que ocorreu em 2008. A entrevistada: Sandra Fávero, artista visual e professora, concedeu gentilmente a entrevista ressaltando a importância de se pensar no artista-professor que se quer formar.

Palavras-Chave: Reforma curricular. Artista-professor.

\begin{abstract}
In view of the proposed curricular reform that is intended to be done in the Visual Arts courses of the State University of Santa Catarina, we sought to interview one of the teachers of the Structuring Faculty of the undergraduate course, to comment on this proposal for reform, as well how to explain the goals and challenges faced in the reform that occurred in 2008. The interviewee: Sandra Fávero, visual artist and teacher, kindly granted the interview highlighting the importance of thinking about the artist-teacher who wants to be formed.
\end{abstract}

Keywords: Curricular reform. Artist-teacher. 
Figura 1: Sandra Favero

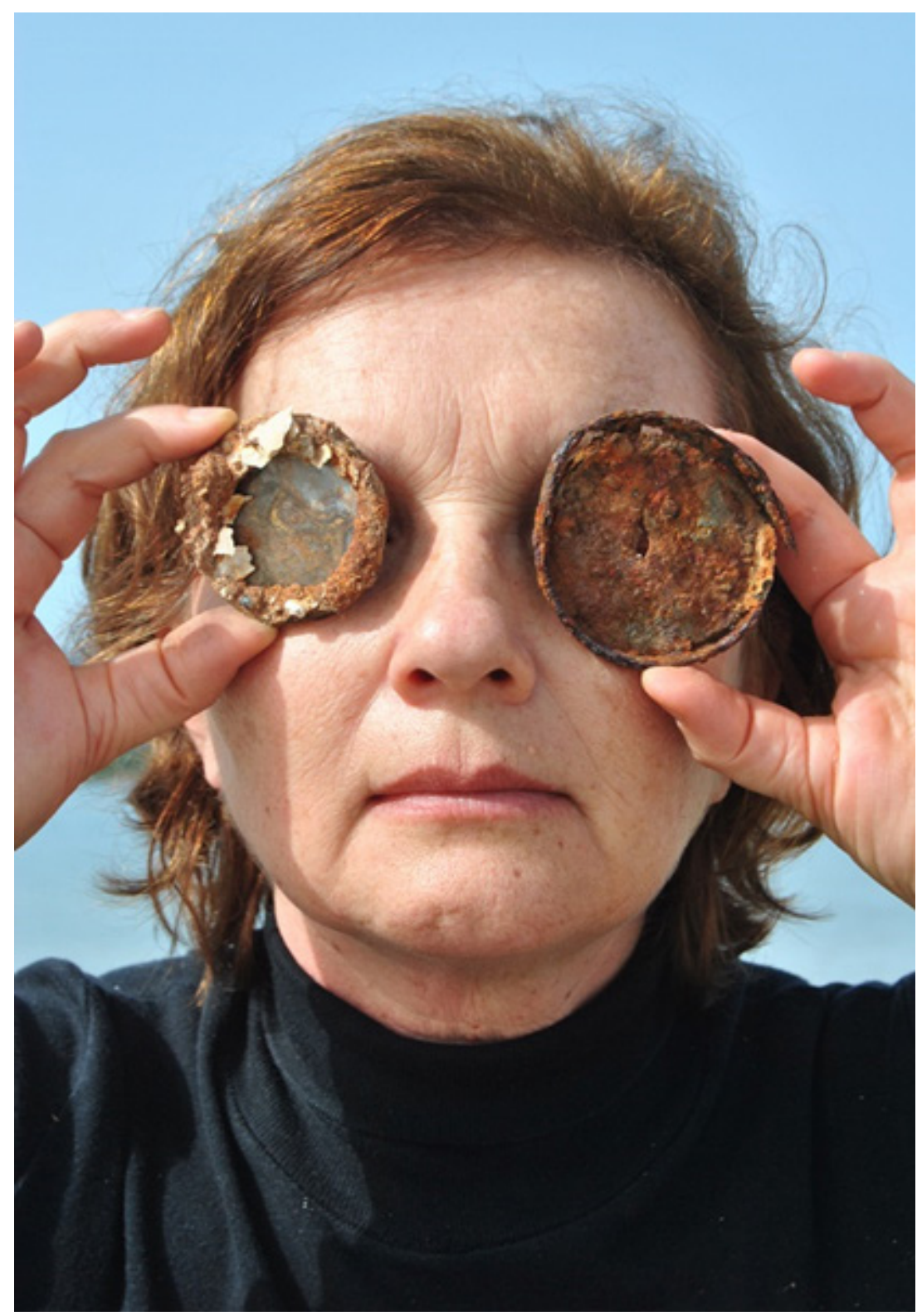

Fonte: Núcleo de Comunicação do CEART. 2015.

Sandra Maria Correia Favero é professora e Entrevistadoras na Universidade do Estado de Santa Catarina, nos cursos de Bacharelado e Licenciatura em Artes Visuais, desde 1998 e no Programa de Pós-Graduação em Artes Visuais, na linha de Processos Artísticos Contemporâneos, desde 2017. Possui doutorado em Poéticas Visuais pela ECA/USP (2015), mestrado em Gestão do Design pela UFSC (2003) e Bacharelado em Pintura pela EMBAP (1979). Atua como curadora em projetos expositivos, desenvolve oficinas para professores, artistas e pessoas interessadas em projetos de extensão universitária relacionados à gravura e livro de artista.

Essa entrevista se realizou nas dependências do Centro de Artes da Universidade do Estado de Santa Catarina durante a primeira semana de maio de 2019 e teve a revisão das respostas gravadas pela própria entrevistada, tendo o formato final como se observa abaixo. 


\section{Entrevistadoras:}

Professora, antes de tudo, gostaria de lhe agradecer por sua disponibilidade em compartilhar um pouco das suas vivências e do seu repertório no espaço das artes e no meio acadêmico, bem como das reflexões a respeito das reformas curriculares no curso de artes visuais da UDESC. Sabemos que sua entrada na UDESC aconteceu em 1998 e que a senhora já tinha uma produção artística relevante.

a) Então, como a senhora avalia o currículo adotado à época de seu ingresso e as relações de aproximação ou distanciamento com a sua atuação como artista?

b) A dimensão artística de seu trabalho colaborou com o fazer de professora e vice-versa?

\section{Entrevistada:}

Em Curitiba, eu já tinha um trabalho como artista. Após o casamento residi em Florianópolis e retomei meu trabalho artístico. A convite do Janga ${ }^{1}$, realizei minha primeira mostra em Florianópolis e ministrei a oficina de gravura em metal no espaço da Associação de Artes Plásticas da Alfândega ${ }^{2}$ por seis meses. Também, tentei o processo seletivo para ser professora na UDESC por duas vezes. Devido ao nascimento dos meus filhos e ao auxílio que prestei ao meu companheiro à frente dos negócios, distancie-me do espaço das artes por cerca de 10 anos. Em 1998, fui aprovada no concurso público para professora da UDESC e voltar, após uma década afastada do cenário das artes. Foi como se estivesse pisando em um novo planeta.

\section{Entrevistadoras:}

A volta ao universo das artes, antes tão distante, agora estava próximo. Conforme a entrevistada, o repertório artístico na gravura facilitou esse retorno, pois essa era sua área de atuação como artista. Em relação à dimensão artística de seu trabalho ter colaborado na sua atuação como professora e vice-versa, a entrevistada afirmou que sempre se considerou artista, pois seu percurso nas artes começou como artista, com a litografia e a gravura em metal e, após, tornou-se professora. Em 2008 tem-se o registro de uma reforma curricular no Curso de Artes Visuais, a qual inclusive modificou a nomenclatura do curso.

a) Gostaríamos de saber como se deu essa reformar curricular de 2008 a partir de seu ponto de vista e quais eram as inquietações naquele momento?

b) Por que, depois de tantos anos de existência do curso, foi preciso realizar uma reforma curricular?

\section{Entrevistada:}

Foi uma reforma difícil, com contundente resistência dos professores que consideravam o currículo vigente uma proposta com maior flexibilização e, ao mesmo tempo, acolhimento entre os discentes. Isso proporcionava uma formação mais individualizada que ia de encontro aos seus interesses de pesquisa e proporcionava um hibridismo pertinente ao espaço da arte contemporânea.

\footnotetext{
1 João Otávio Neves Filho, o Janga (1946-2018) artista plástico catarinense, crítico de arte e curador. Na década de 80 foi presidente da Associação Catarinense de Artistas Plásticos.

2 Associação Catarinense dos Artistas Plásticos - ACAP foi fundada em 1975 por um grupo de artistas plásticos que desejavam promover e divulgar a arte e a cultura produzidas em Santa Catarina. A associação promove várias atividades em parceria com escolas públicas e privadas, como: exposições, leilões beneficentes, oficinas e cursos. A ACAP localiza-se no Centro de Florianópolis, na Rua Arcipreste Paiva. Mais informações: http://www.acap.art.br/index.php?q=principal. Acesso em maio de 2019.
} 
Muitos interesses estavam em jogo. A matriz curricular era dividida em 3 (três) disciplinas: nível introdutório; nível desenvolvimento; e nível avançado ${ }^{3}$. As disciplinas eram elaboradas como oficinas, os professores as criavam. As aulas/ateliês podiam ser frequentadas pelos alunos até 3 (três) vezes, ou seja, como uma especialização naquela área. O professor tinha a liberdade de criar oficinas que se relacionavam com sua área de interesse e pesquisa. O aluno tinha certa liberdade de escolha e com isso o seu histórico escolar se tornava um espelho dos seus interesses enquanto artista ou educador.

Em paralelo, essa estrutura diferenciada de ensino prejudicava nas equivalências, ou seja, se um aluno pedisse transferência para continuar os estudos em outra instituição, era difícil validar o que havia sido estudado devido à forma como se dava a estruturação das disciplinas. Os motivos acima pontuados e outras importantes questões relacionadas com o contexto daquele momento na universidade levaram os membros do Departamento de Artes Plásticas a enfrentarem a reforma curricular, alterando também o nome do departamento para Departamento de Artes Visuais.

\section{Entrevistadoras:}

Concluída a reforma, veio a sua implantação. Processo que a professora também acompanhou. Dentro dessa segunda etapa, muito importante, mais algumas dúvidas.

a) A senhora recorda quais foram as mudanças relevantes que aconteceram nessa reforma que repercutem até os dias de hoje?

b) Elas contribuíram de alguma maneira para o crescimento, fortalecimento e reconhecimento do Curso de Artes Visuais?

\section{Entrevistada:}

Não tenho dados concretos sobre as repercussões das mudanças até os dias atuais, mas sei que o crescimento dos cursos de Bacharelado e Licenciatura se deu também pela reforma curricular, ajustando-se à Pós-Graduação em Artes Visuais, criada em 2005, através das linhas de pesquisa: Teoria e História das Artes Visuais; Processos Artísticos Contemporâneos e Ensino das Artes Visuais ${ }^{4}$.

\section{Entrevistadoras:}

A professora alertou para o cuidado que se deve ter, a fim de que a valorização da Pós-Graduação não exceda em detrimento dos cursos de Bacharelado e Licenciatura em Artes Visuais, os quais são os basilares para a permanência de toda a estrutura de formação acadêmica na área das Artes Visuais dentro do CEART/UDESC. Um debate sempre muito presente é o perfil do profissional que os currículos definem como pressuposto articulador de todo o projeto. Agora, em 2018 e 2019 o DAV realizou uma nova reforma curricular. Diante desse novo cenário:

a) Quais foram as motivações dessa última reforma?

\footnotetext{
3 A resolução que aprovou a reforma curricular de 2008, bem como o currículo vigente que a entrevistada comentou, pode ser visto em: http://www.secon.udesc.br/consuni/resol/2008/010-2008-cni.pdf. Acesso em Maio de 2019.

4 Programa de Pós-Graduação em Artes Visuais - PPGAV/UDESC: https://www.udesc.br/ceart/ppgav. Criado em 2005 somente com o nível Mestrado, em 2013 foi implantado o nível Doutorado. De acordo com as linhas de pesquisa, o programa nos dois níveis, contempla estudos relacionados à produção plástica, ao ensino/aprendizagem em diferentes contextos e à produção teórica.
} 
b) Durante o movimento de construção do percurso curricular, como se deram as discussões em relação ao perfil profissional que o curso quer formar professor de artes visuais, artista ou professor-artista?

c) E hoje, quando uma nova reforma curricular está em conclusão, quais os desafios a serem enfrentados na sua implantação?

\section{Entrevistada:}

As motivações dessa última reforma foram as obrigatoriedades que a Licenciatura em Artes Visuais precisa cumprir, dentre elas o aumento da carga horária do estágio. Por ter a disciplina Teoria e História da Arte compartilhada com o bacharelado, a reforma curricular se deu tanto no espaço da licenciatura quanto no bacharelado.

No que se refere às discussões do profissional que o curso deseja formar, não houve alterações marcantes diante daquilo que já estava explicitado no currículo vigente a respeito da formação, se artista ou professor. No entanto, acho importante pensar nessa questão, pois a licenciatura de fato forma professores que têm seus espaços de atuação mais definidos, mas quais são as possibilidades do aluno do bacharelado? Ateliês próprios ou de outros artistas, indústria criativa... (com um gesto de suspeita ou dúvida, a entrevistada não concluiu a resposta).

Em relação aos desafios a serem enfrentados quanto à implantação da reforma curricular de 2018/2019, na atual matriz a carga horária de estágio para a licenciatura foi ampliada. Isso, aliado às demais atividades e disciplinas, vai fazer com que o curso ocupe dois turnos do dia do aluno, o que pode prejudicar na conciliação das aulas na universidade e um trabalho. Ainda, no que se refere ao profissional que é formado pelo curso, no ano passado, em um projeto do NDE, enquanto chefe do departamento, convidei egressos do curso para uma conversa com os discentes dos dois cursos, para que relatassem seus percursos como profissionais atuantes na área das Artes Visuais. Alguns deles estão trabalhando em empresas de games e jogos digitais, mas na matriz curricular são poucas as disciplinas que trabalham esse assunto. O ideal seria pensar, constantemente, que profissional é esse que o curso está formando?

\section{Entrevistadoras:}

Pensando nesses mais de 20 anos que a senhora está como professora nos cursos de Artes Visuais e mediante tudo que vivenciou com o antigo, com o novo currículo e, inclusive, com o futuro currículo a ser implantado:

a) Qual a avaliação que a senhora realiza de todas essas mudanças ocorridas nos currículos?

b) Há melhorias para o curso, para os estudantes e para a sociedade catarinense?

c) O cenário atual no Brasil do ensino das Artes Visuais e do campo de exercício da profissão é compatível com os cursos superiores oferecidos na área?

\section{Entrevistada:}

É difícil ter uma resposta que englobe todos esses questionamentos, mas o curso tem uma nota muito boa, quase cinco, e tem muitos alunos de fora, o que nos leva acreditar que tal procura seja baseada em sua qualidade. Para sabermos se os cursos 
superiores oferecidos na área são compatíveis com o cenário atual no Brasil do ensino das Artes Visuais e do campo de exercício da profissão, seria preciso realizar um estudo sobre a situação dos egressos.

\section{Entrevistadoras:}

Para as futuras gerações de formadores em Artes Visuais, o que a senhora julga um ponto incontornável a ser pensado, tomado mesmo como bandeira?

\section{Entrevistada:}

É preciso pensar nessa nova geração de alunos que é diferente dos alunos de 20 anos atrás quando entrei na docência. Essa nova geração vive no celular, se distrai facilmente, sendo difícil prender sua atenção. Sem falar no fato de que entram cada vez mais cedo na universidade, mas, ao mesmo tempo, são esclarecidos, tem posicionamento político e sabem reivindicar seus direitos. Portanto, é preciso pensar como alcançar esses jovens, mostrando a importância das Artes e como a universidade e os professores podem ser relevantes nesse percurso acadêmico e profissional.

\section{Em termos de síntese, últimas palavras:}

A partir da presente entrevista, conhecendo um pouco a trajetória da professora Sandra e dos percursos do próprio curso de Artes Visuais, perceberam-se movimentos e recomeços. Ou seja, viu-se a artista que se afastou das artes durante uma década e, após, adentrou em um cenário novo que Ihe exigiu uma vivência que não tinha enquanto professora. Foi preciso construir uma professora-artista ou artista-professora nesse fazer dinâmico da docência e da própria artisticidade. Como docente, observou um modelo formador amplo que não atendia mais o contexto contemporâneo que precisava contemplar outros fazeres além das artes plásticas. E, segundo ela, foi preciso avaliar e observar onde estavam os egressos artistas e professores. Atualmente, é outro momento de pausa, de avaliar e recomeçar, observando as necessidades desse contexto, do ensino das artes e levar em consideração o profissional contemporâneo que é jovem e conectado ao mesmo tempo em que é também crítico.

Agradecemos a disponibilidade e o carinho com que a professora e artista Sandra Fávero nos atendeu.

DOI: http://dx.doi.org/10.5965/25944630322019112 